\title{
Flow analysis of a radial-inflow variable geometry turbine stator vane ring using particle image velocimetry
}

\section{Citation for published version (APA):}

Rijk, de, L., Eichhorn, R. H. L., Boot, M. D., \& Smeulders, D. M. J. (2012). Flow analysis of a radial-inflow variable geometry turbine stator vane ring using particle image velocimetry. Journal of Flow Visualization and Image Processing, 19(3), 195-213. https://doi.org/10.1615/JFlowVisImageProc.2013006729

DOI:

10.1615/JFlowVisImageProc.2013006729

Document status and date:

Published: 01/01/2012

\section{Document Version:}

Accepted manuscript including changes made at the peer-review stage

\section{Please check the document version of this publication:}

- A submitted manuscript is the version of the article upon submission and before peer-review. There can be important differences between the submitted version and the official published version of record. People interested in the research are advised to contact the author for the final version of the publication, or visit the $\mathrm{DOI}$ to the publisher's website.

- The final author version and the galley proof are versions of the publication after peer review.

- The final published version features the final layout of the paper including the volume, issue and page numbers.

Link to publication

\section{General rights}

Copyright and moral rights for the publications made accessible in the public portal are retained by the authors and/or other copyright owners and it is a condition of accessing publications that users recognise and abide by the legal requirements associated with these rights.

- Users may download and print one copy of any publication from the public portal for the purpose of private study or research.

- You may not further distribute the material or use it for any profit-making activity or commercial gain

- You may freely distribute the URL identifying the publication in the public portal.

If the publication is distributed under the terms of Article 25fa of the Dutch Copyright Act, indicated by the "Taverne" license above, please follow below link for the End User Agreement:

www.tue.nl/taverne

Take down policy

If you believe that this document breaches copyright please contact us at:

openaccess@tue.nl

providing details and we will investigate your claim. 


\title{
Flow Analysis of a Radial-inflow Variable Geometry Turbine Stator Vane Ring using PIV.
}

\author{
Author: $\quad$ ir. Lex Leendert (L.L.) de Rijk, e-mail: 1.l.d.rijk@student.tue.nl \\ Co-Authors: ir. R.H.L. Eichhorn, e-mail: r.h.l.eichhorn@tue.nl \\ prof.dr.ir. D.M.J. Smeulders, \\ dr.ir. M.D. Boot
}

Section Engineering Thermodynamics for Energy Systems, Department of Mechanical Engineering, Eindhoven University of Technology, Den Dolech 2, 5612AZ Eindhoven, The Netherlands.

\begin{abstract}
An optimization at the lower off-design mass flow range of the radial-inflow variable geometry turbine is required for future turbine applications. One of these applications is using this type of turbine as the throttling apparatus for a spark ignition engine to recover energy which is wasted by the conventional throttle. A wide operating mass flow range with significant turbine efficiency is needed for these applications. The stator-to-rotor interaction is optimized of a standard radialinflow turbine by changing the variable-vane-angle stator vane ring geometry.

The flow at the conventional and a new design stator vane ring is analyzed using particle image velocimetry (PIV) with the intention of using the results to substantiate the increase of performance of the new turbine with new designed stator vane ring and for the admittance of computational fluid dynamic simulations. A PIV experimental setup is built to visualize the jet flow between and directly downstream the stator vanes. Two-dimensional steady-state jet-flow characteristics are mapped at several stator vane positions. Two series of fixed positioned stator vane rings are fabricated by rapid prototyping which represent the original and new variable-vaneangle stators. The flow characteristics of both series of vane rings are compared.
\end{abstract}

Key words: variable geometry turbine, vaneless space, mass-flow range extension, flow visualization.

\section{Nomenclature}

\begin{tabular}{ll} 
& \multicolumn{1}{c}{ Roman Symbols } \\
$C$ & Absolute velocity \\
$D$ & Diameter \\
$I$ & Momentum \\
$I^{*}$ & Mass-flow normalized Momentum \\
$l_{t h 2}$ & Vane throat width \\
$l_{v 1}$ & Pivot-to-leading edge distance \\
$l_{v 2}$ & Pivot-to-trailing edge distance \\
$N_{v}$ & Number of stator vanes \\
$p$ & Pressure \\
$r_{i}$ & Radius with vane-ring midpoint \\
& base, with i $=2,3,4$
\end{tabular}

\begin{tabular}{ll} 
& \multicolumn{1}{c}{ Greek symbols } \\
$\alpha_{2}$ & Vane angle and flow angle at vane throat \\
$\alpha_{3}$ & Flow angle at stator exit \\
$\alpha_{4}$ & Flow angle at rotor inlet \\
$\theta$ & Circumferential vane ring angle \\
$\rho$ & Air density \\
& $\quad$ Subscripts \\
2 & Position: Stator throat \\
3 & Position: Stator outlet \\
4 & Position: Rotor inlet \\
$C$ & Conventional \\
$N$ & New
\end{tabular}




\section{Introduction}

The gas-dynamic interaction between the stator and rotor is of great importance for the turbine efficiency of the variable geometry radial-inflow turbine. The reduction of the vaneless space (stator-to-rotor clearance) has proven to increase the turbine efficiency at low off-design massflow rates from earlier tests. To reduce the vaneless space the pivot of the variable-position stator vanes is repositioned to the trailing edge of the vane and placed near to the rotor-blade-tip perimeter. A relative difference in turbine efficiency of this modified vane ring to the conventional vane ring of $60 \%$ to $0 \%$ is reached, over the mass-flow range of $33 \mathrm{~kg} / \mathrm{h}$ to $110 \mathrm{~kg} / \mathrm{h}$, respectively without affecting the efficiency around the turbine design point of the Garret GT1541V turbocharger turbine. Interesting applications of this new design are valves in gas pipelines and recuperative throttling of the spark ignition engine. Earlier work on the latter application is done by Eichhorn, Boot, and Luijten (2009),(2010).

A better understanding of the flow within the vaneless space must be realized to substantiate the turbine efficiency results.

\section{Flow Measuring Technique}

\subsection{PIV}

Particle Image Velocimetry is an optical planar measurement technique which is used to determine the velocity-vector field over an area with illuminations of in-flow particles illuminated by a LASER sheet, Raffel, Willert, Wereley, and Kompenhans (2007). Two captured subsequent images with a time shift of a few microseconds are used to determine the velocity field from particle displacements.

An analysis by Particle Image Velocimetry (PIV) is performed on the stator flow to investigate the typical steady-state flow characteristics within the stator vane ring and the vaneless space. A series of fixed position vane rings is manufactured by a Rapid Prototype process which series represent several stator vane ring settings of the conventional and new variable position stator vane ring. No rotor is present at these experiments and an open-loop setup is used with air as the working fluid.

The velocity fields are obtained at the lower mass flow limit of normal turbine operation due to practical difficulties of tracking the PIV seeding. Therefore these experiments are mainly used for qualitative results and comparison. The following objectives are defined for these PIV experiments:

1. To map several steady-state flow characteristics to validate one-dimensional turbine theory.

2. To explain the larger efficiency results of a turbine using a vane ring with reduced vaneless space.

3. To collect velocity fields which can be used for subsequent Computational Fluid Dynamics (CFD) simulations. 


\subsection{Test rig and test vane ring}

A schematic view of the experimental setup is given in figure 1. A vane ring is shown in top view and side view. A series of rapid prototyped vane rings are used for these experiments with fixed known vane angle and vane-throat width. Conventional and new vane rings were manufactured in pairs of constant vane throat width. A single vane ring setup is shown in figure 2 .

For LASER access to the vane ring, one vane is replaced by a small quartz plate window. It is assumed to have a minor effect on the flow, especially at the window of interest at the opposite side of the vane ring. Throat widths between the glas vane and the normal vane are comparable with the normal throat widths. A slit diaphragm with a slit of $0.25 \mathrm{~mm}$ is glued on the quartz plate window to create a thinner LASER sheet at the window of interest (see figure 2). The LASER sheet is positioned at mid-height of the vanes. A glass plate is placed on top of the configuration to cover the stator vane ring. Air flows in radially and exits axially. The covering glass plate is used for optical access of the camera which is positioned perpendicular. The geometry near the window of interest is painted using Rhodamine dissolved in varnish. In combination with a narrow band filter mounted on the camera lens, LASER reflections of the geometry are suppressed to a large extent. Seeding is added to the flow by positioning a seeding nozzle by hand using straws. Paraffin oil particles are used for the seeding with a mean particle diameter of $0.21 \mu \mathrm{m}$ and with high grade of uniformity. Using sub- $\mu \mathrm{m}$ particles it is assured that they follow the main turbulent air flow properly.

The LASER pulses are generated by a frequency-doubled dual-cavity $50 \mathrm{~mJ} \mathrm{Nd}$ :YAG LASER $(532 \mathrm{~nm})$ with a maximum repetition rate of $15 \mathrm{~Hz}, 3-5 \mathrm{~ns}$ pulse. A minimum time shift between the double pulse of $1 \mu \mathrm{s}$ can be set. Optics guide the LASER to a sheet which is focussed at the window of interest. The LASER sheet thickness is of the same order as the used slit diaphragm, $0.25 \mathrm{~mm}$. The seeding illuminations from both pulses are captured by a CCD camera (PCO 1600L,1600x1200 pixels with a pixel size of $7.4 \times 7.4 \mu \mathrm{m}^{2}, 14$ bits and $30 \mathrm{fps}$ at full frame). A TV lens $75 \mathrm{~mm}, \mathrm{~F} 1.3$ is used. A $40 \mathrm{~mm}$ C mount is attached. Hereby a magnification factor of 81.3 pixels $/ \mathrm{mm}$ is set. Timing of the camera capturing and LASER pulses is controlled by the specialized software Davis 7.2 Intelligent Imaging.

The air pump reaches a maximum mass flow rate of $80 \mathrm{~kg} / \mathrm{h}$ when no flow restrictions are applied. This is low compared to the flow regime at which the used turbine operates, $40-120 \mathrm{~kg} / \mathrm{h}$, where for low mass flow rates the flow is strongly restricted. The PIV measurements could only be performed at the low turbine operation limit, which is around $40 \mathrm{~kg} / \mathrm{h}$ (dependent on the stator flow area). Therefore the measurements performed by this setup are used for qualitative purpose. It is recommended for future experiments to perform tests at larger mass flow rates.

Definitions and specifications of the stator vane ring geometry of the conventional and new vane ring series used during the PIV experiments are given in table 1 and figure 3. 


\subsection{Data processing}

The mass-flow rate $\dot{m}$, temperatures $T_{a}$ (ambient) and $T_{1}$, and pressures $p_{a}$ (ambient), $p_{1}$ and $p_{2}$ are measured for the purposes:

1. To be able to set these quantities as $\dot{m}$ and $p_{1}$ during PIV measurements,

2. To be able to use these for input parameters for subsequent Computational Fluid Dynamics simulations.

Due to a partially covered window of interest by seeding, numerous subsequent experiments are executed at different seeding-nozzle positions and stator vane ring positions. Extracted steadystate data is joined together. An averaging procedure in MATLAB is executed using multiple measurements to provide velocity profiles. The toolbox PIVMAT is included in MATLAB to process PIV vector field data.

A recording rate of $5 \mathrm{~Hz}$ is set between image pairs. Typical flow velocities lead to seeding displacements of $5-14$ pixels. With a pixel size of $0.0123 \mathrm{~mm}$ the typical displacements lead to absolute velocities of $30-90 \mathrm{~m} / \mathrm{s}$ in horizontal and vertical direction. The images are processed with an initial interrogation window size of $128 \times 128$ pixels and final window size of 32x32 pixels with $75 \%$ window overlap. Non-realistic velocity vectors larger than \pm 14 pixels in horizontal or vertical direction (outliers) are filtered out.

\section{PIV Measurements}

The mass-flow rate is kept more or less constant for each vane ring pair. The set rates are found in table 2. Pressure differences of between 0 to 0.15 bar between ambient pressure and the static pressure downstream the stator vane ring, and temperature differences of $0-5.6 \mathrm{~K}$ between the ambient temperature and static temperature downstream the stator vane ring are measured.

The vane ring is re-adjusted in position in most cases, because the quartz glass window is restricting the LASER sheet width. The measurement area could not be covered fully by proper seeding within one measurement sequence, therefore multiple sequences are performed.

A convergence test resulted in a maximum difference of $1 \%$ of a typical velocity within the air jet between 40 and 80 image pairs. A measurement sequence of 40 successive image pairs was recorded for each measurement, of which 40 velocity-vector fields were produced. Despite the convergence test result it is recommended for future measurements to produce data with a significant larger sequence.

\section{Processed flow field results}

\subsection{Pixel displacement variance}

Fluctuations of velocity at certain locations within the vane ring geometry are present due to the strong turbulent flow and can have an effect on the turbine performance. The conventional and 
new stator vane ring are compared by the pixel displacement variance from the mean displacement of the two velocity components. These components are the radial and tangential velocity at the rotor-blade tip perimeter.

Figure 4 shows the pixel displacement variance distributions of the vane rings with $l_{t h 2}=2 \mathrm{~mm}$. Differences between the distributions of the conventional and new vane rings are small. It is concluded that the turbine efficiency difference between the two applied vane rings is not caused by these differences in fluctuations. This also holds for vane rings with throat widths of 3 and 5 $\mathrm{mm}$ at the specified mass flow rates.

\subsection{Stator-exit flow angle}

The derived flow angle at the stator exit span from the PIV experiments is compared with the flow angle determined by one dimensional flow theory. The theory is given in appendix A.

The transverse and longitudinal velocity profiles $C_{x}$ and $C_{y}$ respectively, along the exit-span line from the PIV data are derived (see figure 5a for definitions). The exit-span line is defined as the line between the trailing edge of the adjacent vane to the trailing edge of the main vane. The velocity contours are shown in the figures $\mathrm{C} 1 \mathrm{a}, \mathrm{b}$, and $\mathrm{c}$ in the appendices. From these contours the stator-exit flow angle is determined. Due to seeding difficulties parts of these contours are missing, nevertheless all stator-exit flow angle contours of the tested conventional and new vane rings are shown in figure 6. Due to wake effects of the vanes and interaction between two jets, the measured flow angle differs from the theoretical determined flow angle at these wake areas along the profile. The theoretical angle corresponds to a flow directed along the longitudinal direction of the main vane. The true flow angle approaches the theoretical value at some point along the span for each vane ring. The air is directed slightly towards the main vane, due to the interaction of the jets causing an overall larger flow angle compared to the theoretical value.

\subsection{Rotor-inlet flow angle}

The derived flow angle at the rotor inlet from the PIV experiments is compared with the flow angle determined by one dimensional flow theory. The theory is given in appendix A.

The theoretical rotor-inlet flow angle is determined using the assumption of constant density between the stator throat and the rotor inlet as well as conservation of momentum in the vaneless space, Watson and Janota (1982). The assumption of constant density is well-founded as an approximation on the maximum reached Mach number is about 0.21 at the PIV experiments. Thus, compressibility effects are neglected.

Following from the assumption of conservation of momentum it holds that $r_{3} C_{t 3}=r_{4} C_{t 4}$. To investigate this assumption, the tangential and radial velocity profile at the (virtual) rotor inlet are determined from the PIV data (see figure $5 \mathrm{~b}$ for the definitions). These velocities are used to determine the rotor-inlet flow angle profile.

Figures $7 \mathrm{a}$ and $\mathrm{b}$ show the results of the conventional and new vane rings. The rotor-inlet flow angle is defined in figure $5 \mathrm{~b} ; \tan \alpha_{4}=\frac{C_{t 4}}{C_{r 4}}$. The radial and tangential velocity profiles used for 
the determination of the rotor-inlet flow angle are determined along a periodic circumferential perimeter section with radius $r_{4}$ covering $\frac{1}{N_{v}}$ of the entire perimeter, where $N_{v}$ is defined as the number of stator vanes.

For the conventional vane rings it is concluded that for all three vane angle settings the velocity fluctuations in tangential and radial directions along the perimeter have dampened out due to the relatively long residence time of the air in the vaneless space. No distinction is found between circumferential jet and wake sections. For the new vane rings it is clearly seen that jets and wakes are still present at the rotor inlet perimeter caused by the smaller vaneless space. The jets are found at the angle minima, as they create a more radially directed flow at the rotor-tip perimeter. As the work extracted by the rotor is obtained from the circumferential velocity according to the one-dimensional modeling, this could be a disadvantage of the new vane rings. However, a section of more tangentially directed flow is found as well at all three new vane rings.

The experimentally-determined mean flow angles are similar to the theoretical values for all investigated vane rings, except for the conventional vane ring with a relatively small vane throat of $2 \mathrm{~mm}$. A larger flow angle is measured compared to the theoretical value with a difference of about 6 degrees. It is expected that at these circumstances the air loses a significant amount of momentum due to dissipation effects along the long distance of the flow path through the vaneless space.

\subsection{Rotor-inlet momentum}

The air momentum crossing the rotor-inlet perimeter is determined from the derived radial and circumferential velocity contours. To avoid differences in momentum caused by the effective mass flow the momentum is normalized by the mass flow rate determined by the same derived velocity contours. The mass-flow-normalized momentum in radial and tangential direction is expressed as:

$$
\begin{array}{rlr}
I_{r}^{*}=\frac{I_{r}}{\dot{m}_{2 D}}=\frac{\int_{0}^{\frac{2 \pi}{10}} C_{r 4}^{2}(\theta) d \theta}{\int_{0}^{\frac{2 \pi}{10}} C_{r 4}(\theta) d \theta}, & {[\mathrm{m} / \mathrm{s}]} \\
I_{t}^{*}=\frac{I_{t}}{\dot{m}_{2 D}}=\frac{\int_{0}^{\frac{2 \pi}{10}} C_{r 4}(\theta) C_{t 4}(\theta) d \theta}{\int_{0}^{\frac{2 \pi}{10}} C_{r 4}(\theta) d \theta}, & {[\mathrm{m} / \mathrm{s}]}
\end{array}
$$

With $\dot{m}_{2 D}$ the in-plane mass flow rate within the radial-tangential plane. These expressions follow from the procedure given in appendix B. Integration over the momentum profiles is performed by mid-point rule to determine the total normalized momentum at the rotor-inlet perimeter.

The normalized momentum values are given in table 3. Larger values in radial direction are obtained for the new vane rings, especially for smaller vane widths. Relative differences of the normalized radial momentum between the vane types are: $74 \%, 24 \%$, and $4.9 \%$ of the vane widths of 2,3 , and $5 \mathrm{~mm}$, respectively. A total-momentum difference of $9.24 \%, 5.38 \%$, and $-4.37 \%$ is found, respectively. 
It is concluded that the air has more radial momentum at the rotor inlet of the new turbine system compared with the conventional system with the same stator-throat width and mass-flow rate. Reducing the vaneless space causes a more fluctuating velocity profile with larger velocity amplitudes along the rotor-tip perimeter. From the results of this work it is concluded that this has no negative effect on the total momentum passing the rotor inlet.

\section{Conclusions}

A larger turbine efficiency is obtained within the low off-design mass flow range by reducing the vaneless space between the variable-vane-position stator and the rotor at earlier experiments. To substantiate these results the flow within the stator and vaneless space is further investigated using the Particle Image Velocimetry technique with series of fixed-vaned rapid-prototyped stator vane rings. A PIV setup is realized with particular focus on LASER entrainment and proper image capturing of a high turbulent flow.

This paper illustrates several flow characteristics within the vaneless space between stator and rotor using the built PIV setup:

1. Velocity-fluctuation variances from the mean velocity profiles caused by the highly turbulent flow are similar for conventional and new stator vane rings at the virtual rotor inlet. These fluctuations are expected not to be responsible for the radial momentum difference between conventional and new vane rings.

2. The mean true stator outlet flow angle along the exit span of the vanes is larger than the theoretical determined flow angle due to the interaction between adjacent jets exiting the stator geometry.

3. The mean true rotor inlet flow angle corresponds to the theoretical determined flow angle, though for the new vane rings this angle deviates along the blade-tip perimeter due to the reduced vaneless space. An exception is obtained for small stator openings of the conventional vane ring. The conserved momentum assumption across the vaneless space does not hold at these conditions.

4. A larger total momentum reaches the blade-tip perimeter for the new stator vane rings with reduced vaneless space compared to the conventional stator vane ring. This induces a smaller flow path between stator and rotor at small stator openings.

The larger turbine efficiency at low off-design mass flow rates using the new stator vane ring is the result of a larger total momentum passing the rotor inlet, especially for small stator openings. Dissipation of energy within the vaneless space due to mixing effects has a significant negative effect on the turbine efficiency. The dissipative effect even increases a lot more when the opening is this small, that the air swirls around the rotor, causing a sink effect. The smaller vaneless space results in shorter flow paths within the vaneless space and reduces the dissipation. Care has to be taken when reducing the vaneless space. The air should accelerate fully within the stator resulting in a full static pressure drop. It was seen during the experiments that at fully open 
position the air accelerated within the virtual rotor volume as well. This could have a negative influence on the turbine efficiency. Also, the decreased vaneless space could result in a larger noise level.

\section{Acknowledgements}

The authors gratefully acknowledge financial support from AgentschapNL grant (Eureka Project: 5765 WETREN) 


\section{Figures}

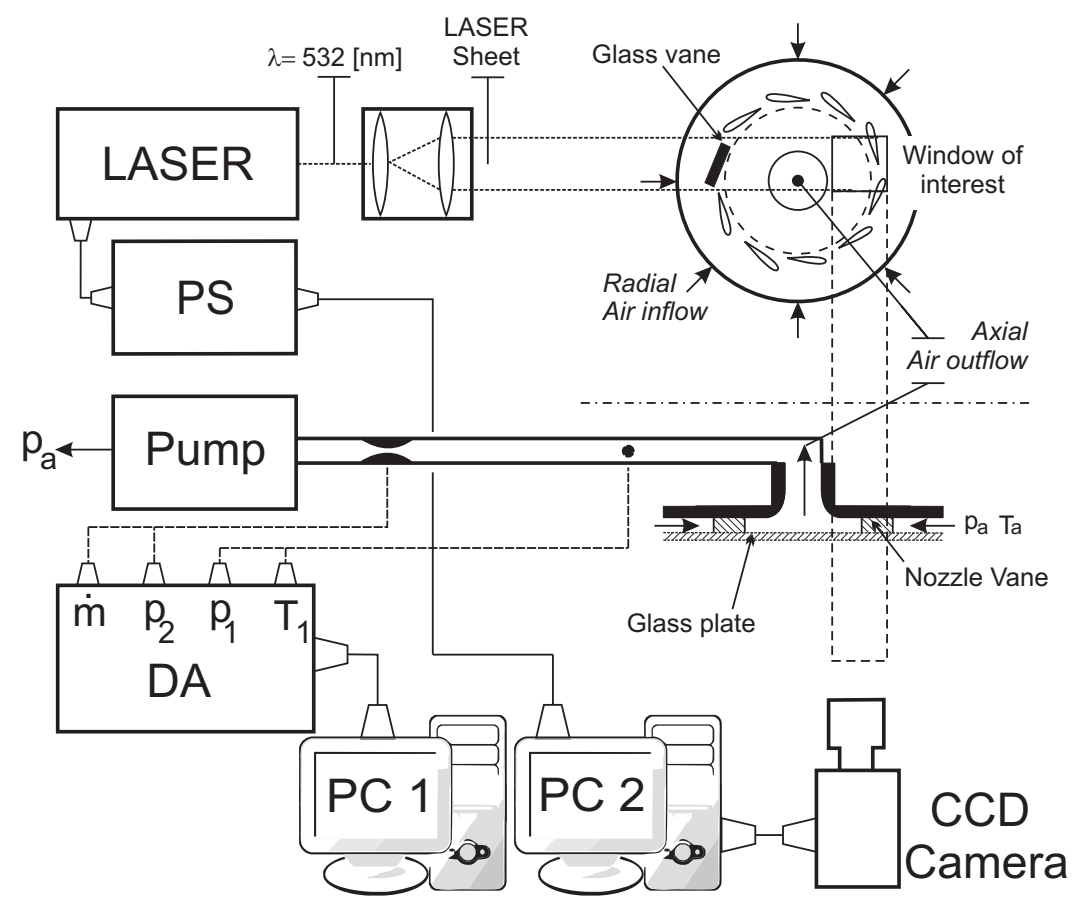

Figure 1

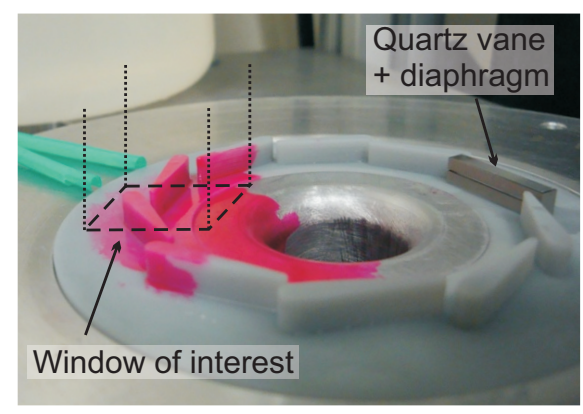

Figure 2 


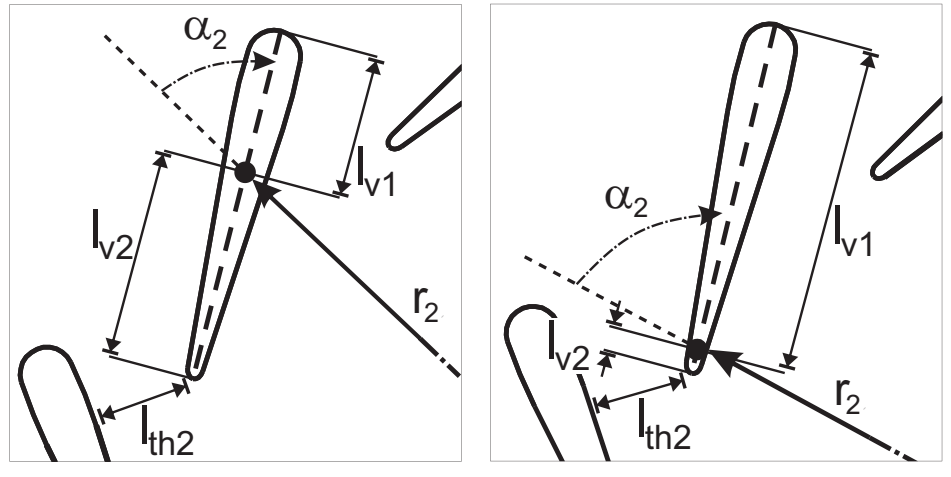

Figure 3
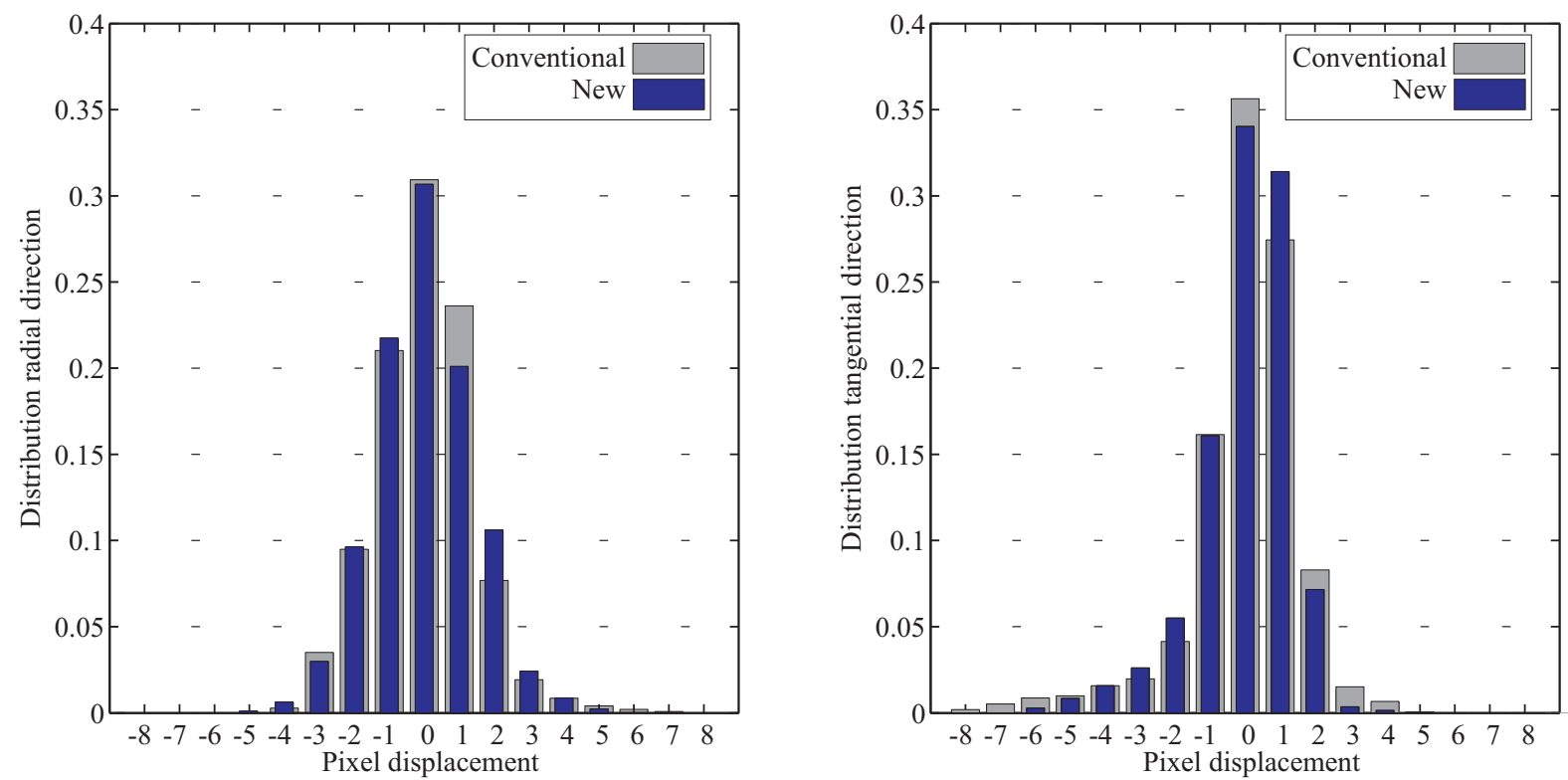

Figure 4: a, b 

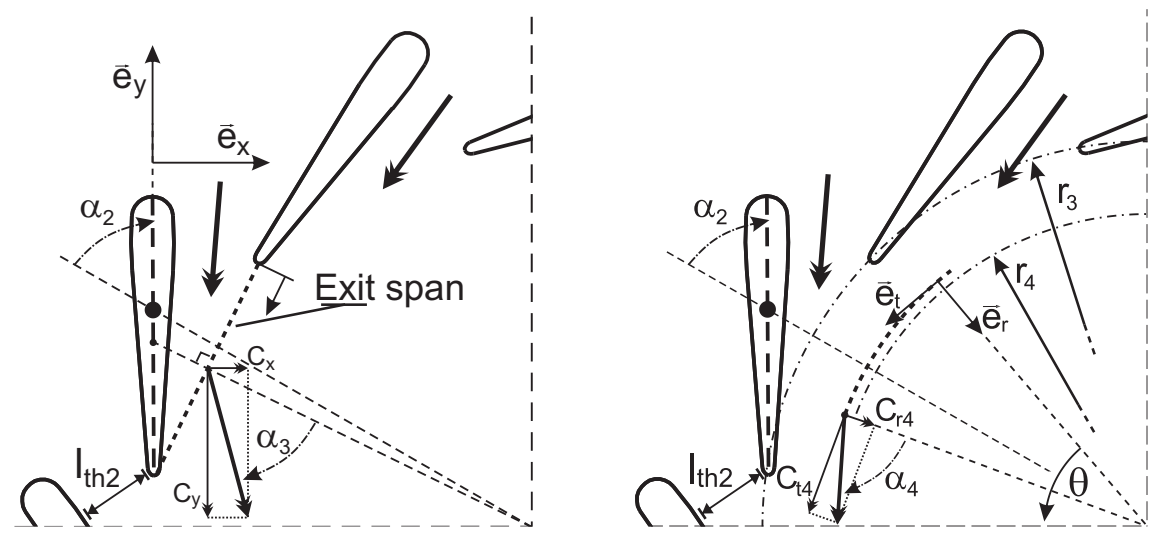

Figure 5: a, b
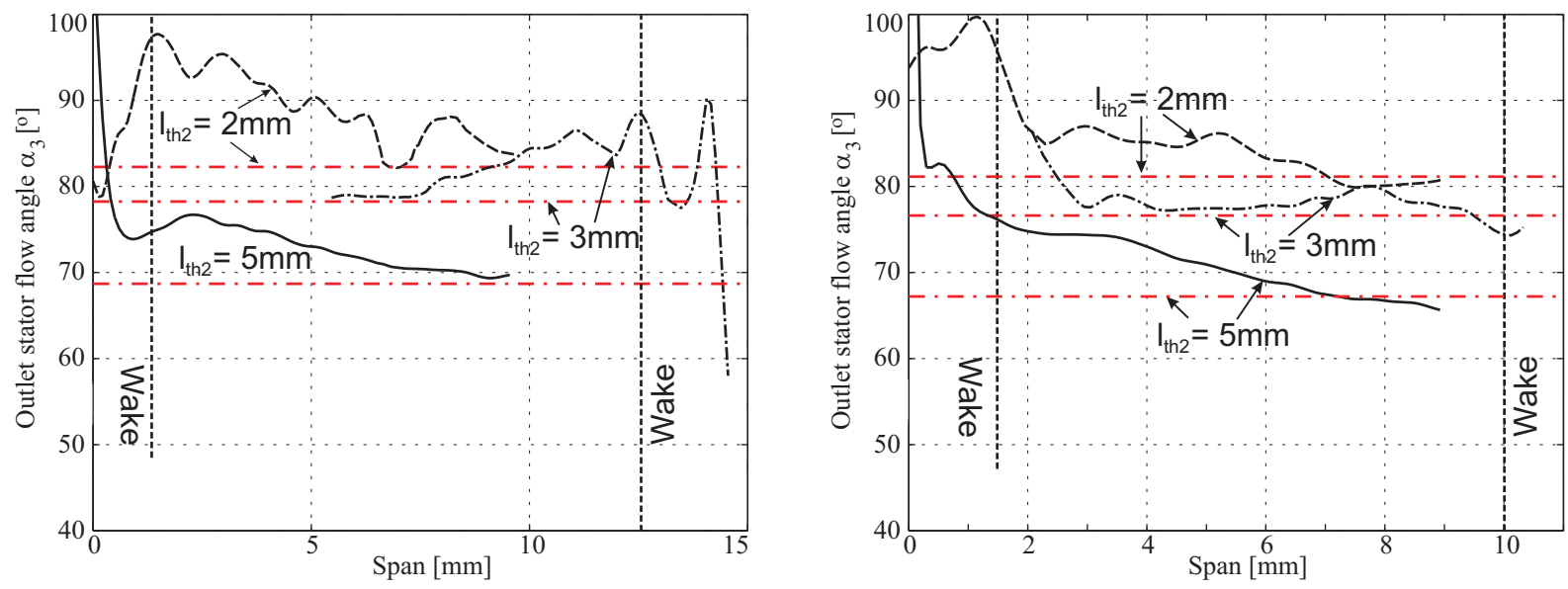

Figure 6: a, b 

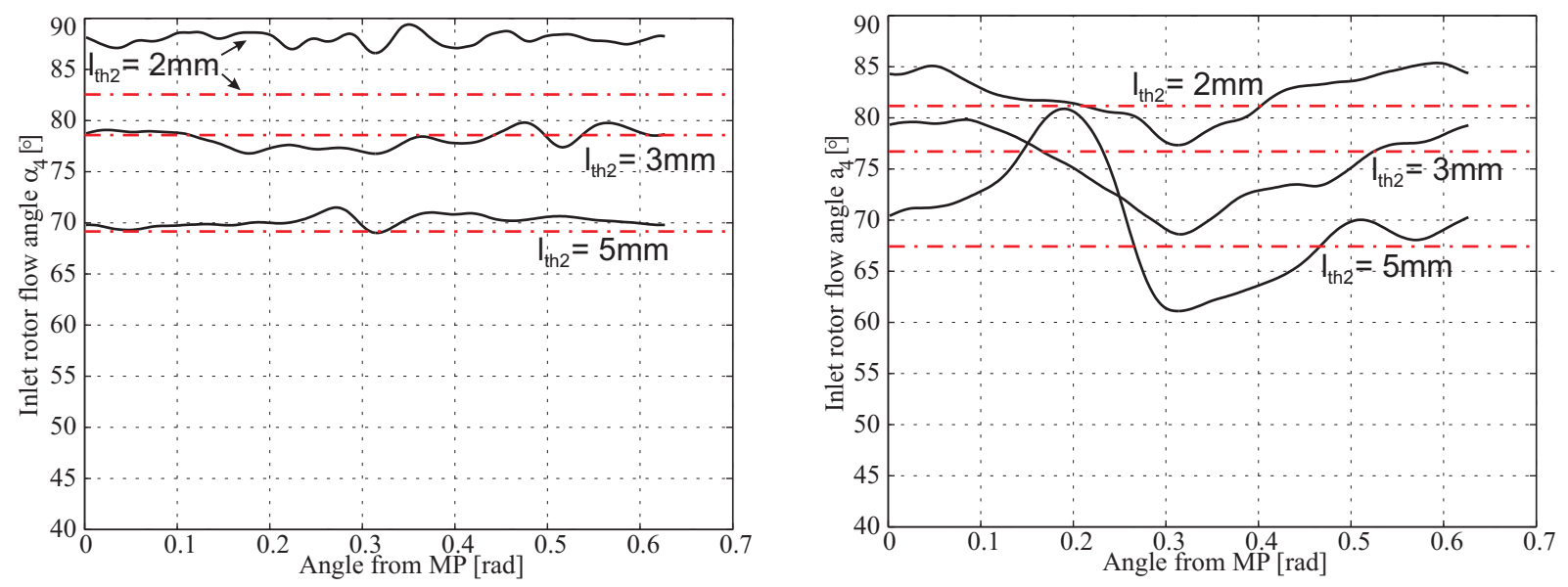

Figure 7: $a, b$

\section{Figure Captions}

1. Schematic view of the experimental setup; DA: Data Acquisition, PS: Power Supply.

2. The stator vane ring setup. The area at the window of interest is painted fluorescent. The quartz-glass window including the glued-on diaphragm is placed at the opposite side of the window of interest.

3. RPT stator vane ring geometry, conventional and new.

4. Displacement distributions with mean displacement reference of the vane ring with $l_{t h 2}=2$ $\mathrm{mm}$ of the conventional and new vane ring at the rotor-blade tip perimeter. a. Radial pixel displacement. b. Tangential pixel displacement.

5. Schematic views of the stator vane ring. Velocity components are directly determined from the PIV velocity fields. a. The defined stator-exit flow angle $\alpha_{3}$ is defined as the angle between the flow direction and the normal of the stator-exit span. b. The radial and circumferential velocity components along the rotor-tip radius $r_{4}$ along the periodic $\theta$ range.

6. The stator-exit flow angle $\alpha_{3}$ of both types of vane rings. The wake lines represent the highly fluctuating flow caused by the wakes at the trailing edges at the adjacent and main vanes. The horizontal lines indicate the theoretical flow angle. a. Conventional vane rings; Total span length: $15.4,15.0$ and $14.0 \mathrm{~mm}$ b. New vane rings; Total span length: 12.4, 12.4 and $12.4 \mathrm{~mm}$

7. The rotor-inlet flow angle $\alpha_{4}$ of both types of vane rings from one-dimensional theory and PIV measurements. The horizontal lines indicate the theoretical flow angle. a. Conventional vane rings $\mathbf{b}$. New vane rings 


\section{Tables}

Table 1: RPT stator vane ring parameters, conventional and new.

\begin{tabular}{lll} 
& \multicolumn{2}{c}{ Vane Ring } \\
Parameter & Conventional & New \\
\hline$r_{2}[\mathrm{~mm}]$ & 26.6 & 21 \\
$l_{v 1}[\mathrm{~mm}]$ & 8.3 & 16.8 \\
$l_{v 2}[\mathrm{~mm}]$ & 9 & 0.5 \\
$l_{t h 2}[\mathrm{~mm}]$ & $2,3,5$ & $2,3,5$ \\
$\alpha_{2}\left[^{\circ}\right]$ & $76,72,62$ & $91,87,77$
\end{tabular}

Table 2: Mass flow rates of the tested RPT vane rings by PIV.

\begin{tabular}{clllll} 
Conventional & $l_{t h 2}[\mathrm{~mm}]$ & $\dot{m}[\mathrm{~kg} / \mathrm{h}]$ & New & $l_{t h 2}[\mathrm{~mm}]$ & $\dot{m}[\mathrm{~kg} / \mathrm{h}]$ \\
\hline 2 & 39 & 2 & 38 \\
3 & 42 & 3 & 41 \\
5 & 46 & 5 & 46
\end{tabular}

Table 3: The mass-flow normalized tangential and radial momentum values of the conventional and new vane rings.

\begin{tabular}{clllllll} 
Conv. & $l_{t h 2}[\mathrm{~mm}]$ & $I_{r}^{*}[\mathrm{~m} / \mathrm{s}]$ & $I_{t}^{*}[\mathrm{~m} / \mathrm{s}]$ & New & $l_{t h 2}[\mathrm{~mm}]$ & $I_{r}^{*}[\mathrm{~m} / \mathrm{s}]$ & $I_{t}^{*}[\mathrm{~m} / \mathrm{s}]$ \\
\hline 2 & 2.86 & 75.81 & 2 & 11.11 & 75.57 \\
3 & 13.46 & 64.10 & 3 & 17.69 & 64.28 \\
5 & 19.19 & 53.14 & 5 & 20.18 & 48.99
\end{tabular}




\section{References}

Eichhorn, R., Boot, M., \& Luijten, C. (2009). Waste energy driven air conditioning system (WEDACS). SAE International, 2009-24-0063.

Eichhorn, R., Boot, M., \& Luijten, C. (2010). Throttle loss recovery using a variable geometry turbine. SAE International, 2010-01-1441.

Hiett, G., \& Johnston, I. (n.d.). Experiments concerning the aerodynamic performance of inward flow radial turbines. Proceedings of the Institution of Mechanical Engineers, 178, Pt 31(II).

Kessel, J., Schaffnit, J., \& Smidt, M. (1998). Modelling and real-time simulation of a turbocharger with variable turbine geometry (vtg). SAE International, 980770.

Raffel, M., Willert, C., Wereley, S., \& Kompenhans, J. (2007). Particle image velocimetry - a practical guide. Springer.

Watson, N., \& Janota, M. (1982). Turbocharging the internal combustion engine. The MacMillan Press ltd. 


\section{Appendices}

\section{A Stator flow theory}

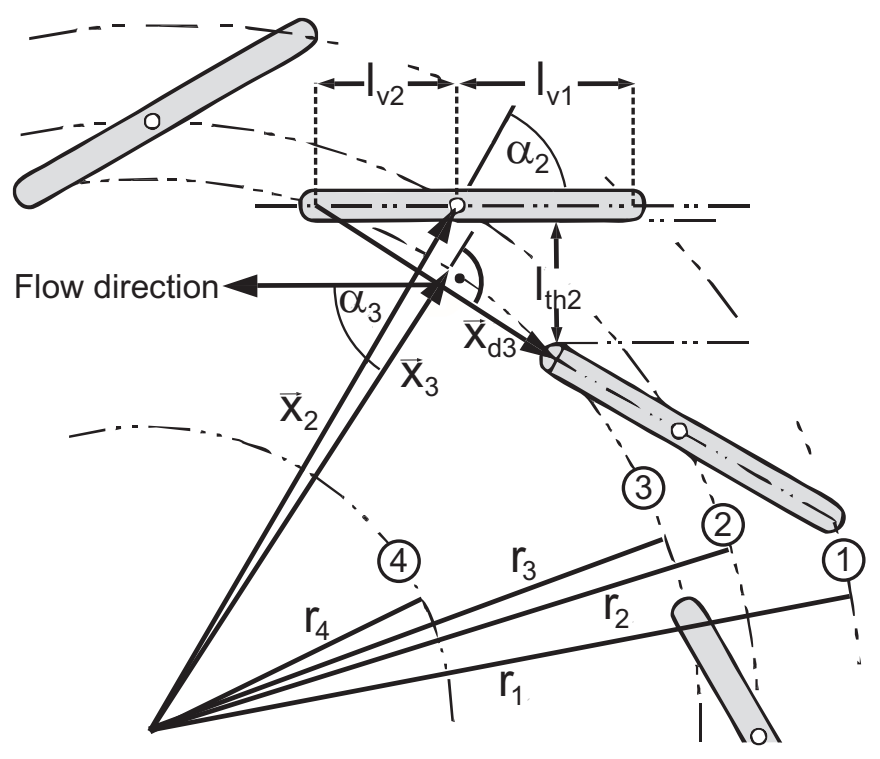

Figure A1: A schematic view of the stator vane ring of the radial-inflow turbine.

The throat width between two stator vanes $l_{t h 2}$ of the stator vane ring is determined using several geometric parameters defined in figure A1. This method is found in the paper of Kessel, Schaffnit and Smidt Kessel, Schaffnit, and Smidt (1998). The throat width $l_{t h 2}$ (see figure A1) is defined by the span vector $\vec{x}_{d 3}$ at the outlet of the vanes in the $\vec{e}_{y}^{2}$ direction:

$$
l_{t h 2}=\vec{x}_{d 3} \cdot \vec{e}_{y}^{2}=\left|\vec{x}_{d 3}\right| \cos \alpha_{3}=s p_{3} \cos \alpha_{3},
$$

where $s p_{3}$ is the span and $\alpha_{3}$ the flow angle at the outlet of the stator. This flow angle is assumed to be equal to the geometric angle between the lateral direction of the vane $\vec{e}_{x}^{2}$ and the normal to the stator exit-span direction. In other words, it is assumed that the flow direction is of lateral direction of the vane at the stator exit, position (3). Watson and Janota Watson and Janota (1982) discuss this assumption (originally assumed in the paper of Hiett and Johnston Hiett and Johnston (n.d.)) and concludes that this is a proper approximation especially at large blade angles, thus at near-closed position of the vanes.

The following definitions are made from figure A1:

$$
\begin{aligned}
\vec{x}_{E} & =\vec{x}_{2}+\vec{l}_{N}=\left[r_{2}, 0\right] \vec{e}^{1}+\left[\begin{array}{ll}
-l_{v 2}, & 0
\end{array}\right] \vec{e}^{2}, \\
\vec{x}_{E N} & =M_{N} \cdot \vec{x}_{E}, \\
\vec{x}_{d 3} & =\vec{x}_{E}-\vec{x}_{E N},
\end{aligned}
$$


where $\vec{l}_{N}$ is the vector from the pivoting point of the vane to the trailing edge. $l_{v 2}$ is the pivotto-trailing edge distance of the vane. $M_{N}$ is the transformation matrix using the defined angle $\alpha_{v}$ along which angle the transformation occurs. This matrix is defined as:

$$
M_{N}=\left[\begin{array}{cc}
\cos \alpha_{v} & \sin \alpha_{v} \\
-\sin \alpha_{v} & \cos \alpha_{v}
\end{array}\right]
$$

where $\alpha_{v}=2 \pi / N_{v}$ with $N_{v}$ the number of stator vanes. The vector $\vec{x}_{E}$ is fully expressed in terms of $\vec{e}^{2}$ using the following transformation:

$$
\vec{e}^{1}=\left[\begin{array}{cc}
\cos \alpha_{2} & -\sin \alpha_{2} \\
\sin \alpha_{2} & \cos \alpha_{2}
\end{array}\right] \vec{e}^{2}
$$

From the span in vector notation $\vec{x}_{d 3}$ the theoretical throat width $l_{t h 2}^{*}$ is determined. Note that a correction must be added on the theoretical throat width by taking into account the vane thickness. The real throat width $l_{t h 2}=l_{t h 2}^{*}-d_{v}$, where $d_{v}$ is the thickness at the throat position on the vane. In many cases $d_{v}$ is taken constant, but it has to be kept in mind that the effective vane thickness at the throat changes when aero-foil-shaped vanes are rotated around their pivot. Once the real throat width is known the stator-exit flow angle $\alpha_{3}$ is determined from equation A.1.

The different geometric total flow areas within the stator at the positions 1,2 , and 3 are defined as follows:

$$
\begin{aligned}
& A_{1}=\left|\vec{x}_{d 1}\right| h N_{v}=2 \sin \left(\frac{1}{2} \alpha_{v}\right) r_{1} h N_{v}=2 \sin \left(\frac{1}{2} \alpha_{v}\right)\left(r_{2}+l_{v 1} \cos \alpha_{2}\right) h N_{v}, \\
& A_{2}=l_{t h 2} h N_{v}, \\
& A_{3}=s p_{3} h N_{v},
\end{aligned}
$$

where $h$ is the vane height in the direction perpendicular to the $\left(\vec{e}_{x}^{1}, \vec{e}_{y}^{1}\right)$ plane and $l_{v 1}$ the pivot-toleading edge distance.

Since the vaneless space is relatively small, the assumption of conserved momentum within this vaneless space is used and energy loss by dissipation is neglected (isentropic flow conditions). This means that for the stator outlet and the rotor inlet, it holds that $r_{3} C_{t 3}=r_{4} C_{t 4}$, where $r$ is the radius at given location, $C$ the absolute flow velocity, and subscript $t$ the tangential direction. The conservation of mass between the stator throat and rotor inlet is expressed as:

$$
\dot{m}=l_{t h 2} N_{\nu} \rho_{2} C_{2} h=2 \pi r_{4} \rho_{4} C_{r 4} h,
$$

where $\dot{m}$ is the mass-flow rate through the turbine geometry and $\rho$ is the air density at given position. From the velocity triangles in figure A2 the rotor inlet angle is determined as:

$$
\tan \alpha_{4}=\frac{C_{t 4}}{C_{r 4}}=\frac{2 \pi r_{3}}{l_{t h 2} N_{v}} \frac{C_{t 3}}{C_{2}} \frac{\rho_{4}}{\rho_{2}}
$$

The second expression is determined using the earlier made conserved-momentum assumption. It is assumed that the flow from the throat of the stator to the rotor inlet is incompressible 


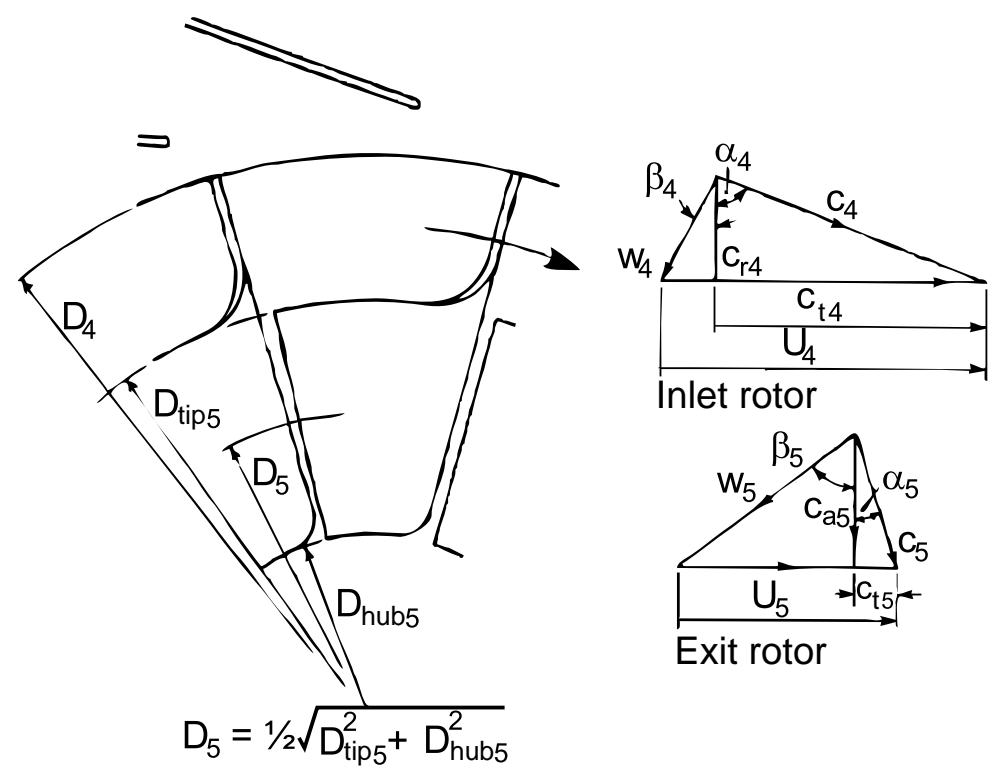

Figure A2: The velocity triangles of the radial-inflow turbine rotor inlet and outlet. The exit diameter is the diameter halfway between the outer diameter of the rotor $D_{\text {tip } 5}$ and the hub or nut diameter of the rotor $D_{h u b 5}$. Also velocity triangles are defined at rotor inlet and outlet.

$\left(\rho_{2}=\rho_{4}\right)$. Since the term $\frac{C_{t 3}}{C_{2}}=\sin \alpha_{3}$, equation A.7 becomes:

$$
\tan \alpha_{4}=\frac{2 \pi r_{3}}{l_{t h 2} N_{v}} \sin \alpha_{3}=\frac{2 \pi\left(r_{2}-l_{v 2} \cos \alpha_{2}\right)}{l_{t h 2} N_{v}} \sin \alpha_{3} .
$$

Equation A.1 is substituted in A. 8 to determine the rotor-inlet flow angle from the vane angle:

$$
\alpha_{4}=\arctan \left[\frac{2 \pi\left(r_{2}-l_{v 2} \cos \alpha_{2}\right)}{l_{t h 2} N_{v}} \sqrt{1-\left(\frac{l_{t h 2}}{s p_{3}}\right)^{2}}\right] .
$$

It is assumed that the stator-exit flow angle $\alpha_{3}$ is similar to the geometric angle of the normal to the span vector to the longitudinal direction of the vane $\vec{e}_{x}^{2}$. This means that the flow direction of the jet within the stator is parallel to the longitudinal direction of the vane. The stator-exit flow angle could deviate from the geometric angle at low vane angles (open position) as the flow experiences less redirection by the stator vane rings. This is thoroughly discussed in Hiett and Johnston Hiett and Johnston (n.d.). The rotor-inlet flow angle $\alpha_{4}$ is thus deviating from the theoretical value as well.

\section{B Mass-flow-normalized momentum}

The equation of the conservation of mass in integral form for steady-state flow condition and two-dimensional flow is expressed as:

$$
\int_{L} \rho(\vec{V} \cdot \vec{n}) d L=0
$$


where $\vec{V}=\left[C_{r 4}(\theta) \vec{e}_{r}, C_{t 4}(\theta) \vec{e}_{t}\right], \vec{n}=\left[\vec{e}_{r}, 0\right]$. Here $L$ is a (periodic) circumferential perimeter section with radius $r_{4}$ covering $\frac{1}{N_{v}}$ of the entire perimeter, where the number of stator vanes $N_{v}=$ 10. As this integral is used in cylindrical coordinates $d L=r_{4} d \theta$. It is assumed that the air density is constant over the perimeter. Including these expressions and assumptions the mass-flow rate crossing the perimeter is expressed as:

$$
\dot{m}_{2 D}=r_{4} \rho \int_{0}^{\frac{2 \pi}{10}} C_{r 4}(\theta) d \theta, \quad[\mathrm{kg} / \mathrm{m} \cdot \mathrm{s}]
$$

From the conservation of momentum in integral form the following expression of the convective term is used for the determination of momentum at the rotor inlet, assuming the steady-state flow condition for two-dimensional flow:

$$
I=\int_{L} \rho \vec{V}(\vec{V} \cdot \vec{n}) d L
$$

The latter expression leads to the following momentum expressions in radial and in tangential direction:

$$
\begin{array}{ll}
I_{r}=r_{4} \rho \int_{0}^{\frac{2 \pi}{10}} C_{r 4}^{2}(\theta) d \theta, & {\left[\mathrm{kg} / \mathrm{s}^{2}\right]} \\
I_{t}=r_{4} \rho \int_{0}^{\frac{2 \pi}{10}} C_{t 4}(\theta) C_{r 4}(\theta) d \theta, & {\left[\mathrm{kg} / \mathrm{s}^{2}\right]}
\end{array}
$$

The mass-flow normalized momentum in radial and tangential direction become:

$$
\begin{array}{rlr}
I_{r}^{*}=\frac{I_{r}}{\dot{m}_{2 D}}=\frac{\int_{0}^{\frac{2 \pi}{10}} C_{r 4}^{2}(\theta) d \theta}{\int_{0}^{\frac{2 \pi}{10}} C_{r 4}(\theta) d \theta}, & {[\mathrm{m} / \mathrm{s}]} \\
I_{t}^{*}=\frac{I_{t}}{\dot{m}_{2 D}}=\frac{\int_{0}^{\frac{2 \pi}{10}} C_{r 4}(\theta) C_{t 4}(\theta) d \theta}{\int_{0}^{\frac{2 \pi}{10}} C_{r 4}(\theta) d \theta}, & {[\mathrm{m} / \mathrm{s}]}
\end{array}
$$




\section{PIV figures}

\section{C.1 Stator outlet velocity contours}
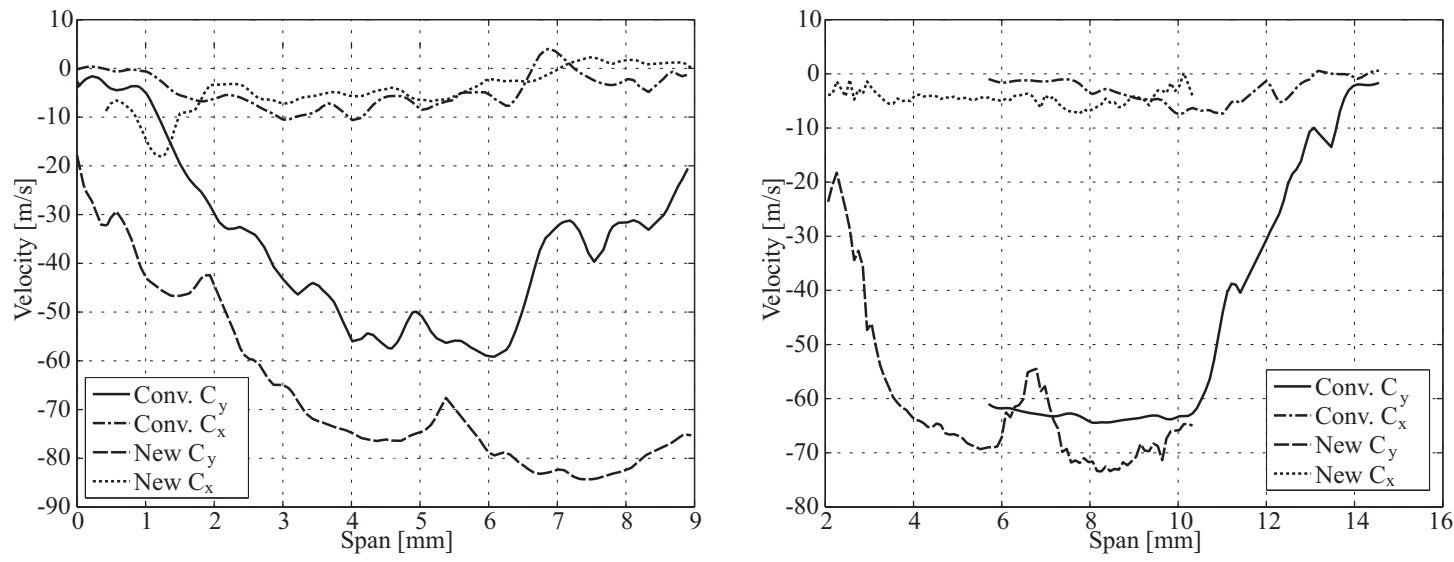

(a) $l_{t h 2}=2 \mathrm{~mm}, \dot{m}_{C}=39 \mathrm{~kg} / \mathrm{h}, \dot{m}_{N}=38 \mathrm{~kg} / \mathrm{h}, \operatorname{span}_{C}$ (b) $l_{t h 2}=3 \mathrm{~mm}, \dot{m}_{C}=42 \mathrm{~kg} / \mathrm{h}, \dot{m}_{N}=41 \mathrm{~kg} / \mathrm{h}, \mathrm{span}_{C}$

$=15.4 \mathrm{~mm}, \operatorname{span}_{N}=12.4 \mathrm{~mm}$ $=15.0 \mathrm{~mm}, \operatorname{span}_{N}=12.4 \mathrm{~mm}$

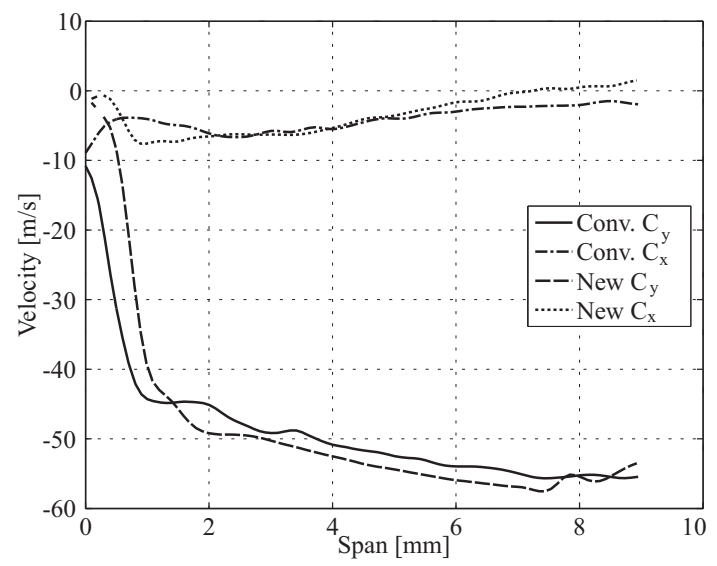

(c) $l_{t h 2}=5 \mathrm{~mm}, \dot{m}_{C}=46 \mathrm{~kg} / \mathrm{h}, \dot{m}_{N}=46 \mathrm{~kg} / \mathrm{h}, \operatorname{span}_{C}$ $=14.0 \mathrm{~mm}, \operatorname{span}_{N}=12.4 \mathrm{~mm}$

Figure $\mathrm{C} 1$ : The transverse and longitudinal velocity profiles, respectively $C_{x}$ and $C_{y}$, along the stator-exit span for the conventional and custom vane rings. 


\section{C.2 Rotor inlet velocity contours}

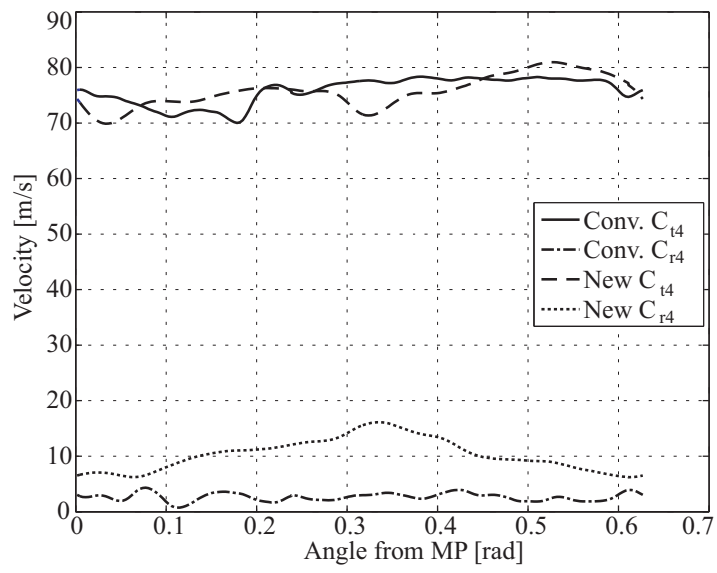

(a) $l_{t h 2}=2 \mathrm{~mm}, \dot{m}_{C}=39 \mathrm{~kg} / \mathrm{h}, \dot{m}_{N}=38 \mathrm{~kg} / \mathrm{h}$

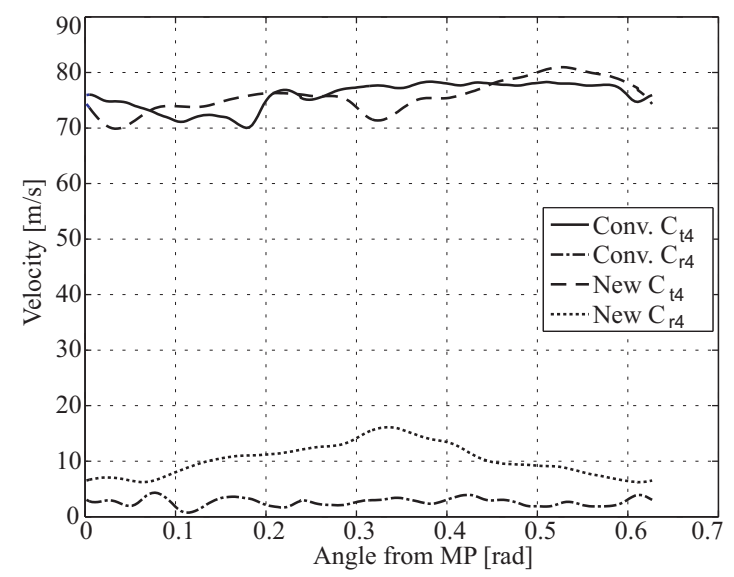

(b) $l_{t h 2}=3 \mathrm{~mm}, \dot{m}_{C}=42 \mathrm{~kg} / \mathrm{h}, \dot{m}_{N}=41 \mathrm{~kg} / \mathrm{h}$

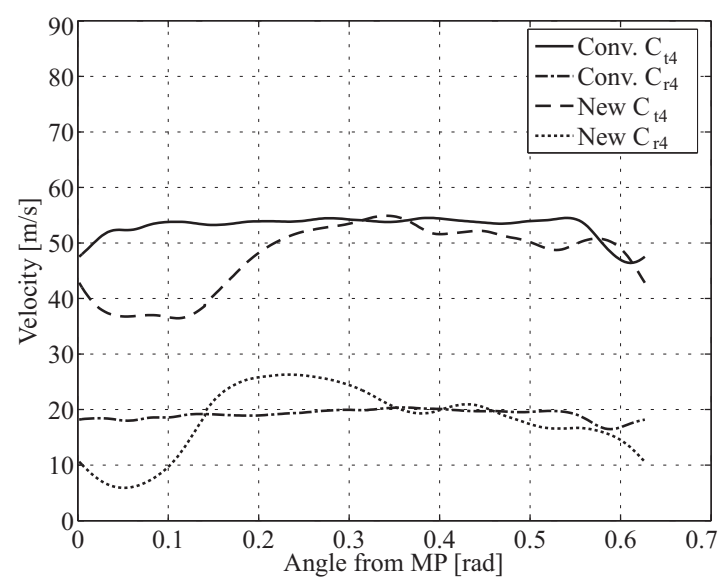

(c) $l_{t h 2}=5 \mathrm{~mm}, \dot{m}_{C}=46 \mathrm{~kg} / \mathrm{h}, \dot{m}_{N}=46 \mathrm{~kg} / \mathrm{h}$

Figure C2: The radial and circumferential periodic velocity profiles, respectively $C_{r 4}$ and $C_{t 4}$, along the blade-tip perimeter of the conventional and new vane rings. 